\title{
A participação da genética nas dependências químicas
}

\section{Guilherme Peres Messas ${ }^{1}$}

\section{Resumo}

Este artigo procura examinar a questão da herdabilidade nas dependências químicas. Através da revisão de estudos em famílias, em gêmeos e de adoção, encontramos evidências para afirmar a importância dos fatores genéticos na transmissão da vulnerabilidade às dependências. Essa transmissão pode ser melhor compreendida através de um modelo epigenético de desenvolvimento do transtorno onde condições biológicas hereditárias associem-se a situações ambientais ao longo da vida para a produção da dependência. Neste artigo apresentamos essas condições biológicas intermediárias vinculadas ao alto risco para dependência, focadas no caso do álcool e da cocaína. Por fim, descrevemos os estudos moleculares que vêm estabelecendo associações entre polimorfismos e as dependências, com relevo para o sistema dopaminérgico.

\section{Descritores}

Dependência de drogas; genética epidemiológica; genética molecular, álcool; cocaína; modelo epigenético

\begin{abstract}
We examined in this article the herdability of drug addiction. Family, twin and adoption sudies reviewed allow us to support the thesis of an important genetic component in drug addiction. The trasmission of this herdability occurs through a biological vulnerability associated to environmental factors, in a model called epigenetic. We also discuss the relationship between biological vulnerability and high-risk phenotypes, focusing on alcohol and cocaine. At the end, we present molecular genetic studies associated with these disorders.
\end{abstract}

\section{Keywords}

Drug addiction; genetic epidemiology; molecular genetics; alcohol; cocaine; epigenetic model

\section{Introdução}

O estudo do componente genético nas dependências químicas sofre da mesma dificuldade experimentada pelos demais transtornos da psiquiatria: a indefinição fenotípica, ou seja, a dificuldade de delimitar fronteiras claras para as categorias diagnósticas. ${ }^{1}$ No entanto, diversos estudos vêm examinando o tema, com resultados significativos, que apresentaremos mais abaixo. Apresentaremos os estudos divididos em dois grupos, os estudos epidemiológicos e os moleculares. Os primeiros fornecem a base empírica para a realização dos segundos, orientando quais fenótipos podem ser mais influenciados geneticamente e, assim, mais férteis para a análise molecular. Chamaremos inicialmente de dependências químicas o amplo e heterogêneo terreno que reúne as dependências a qualquer substância, lícita ou ilícita, de uso nocivo, já que há considerável sobreposição entre as diversas categorias nosográficas de dependência. No entanto, ao longo da exposição, lançaremos o foco à dependência de álcool e de cocaína, pelo número mais volumoso de estudos no primeiro caso e pela importância atual em termos de saúde pública no segundo caso, servindo ambos como modelos gerais para os grupos das dependências.

\section{Estudos epidemiológicos}

Os estudos epidemiológicos dividem-se em três modalidades, os estudos em famílias, em gêmeos e de adoção. Os primeiros demonstram uma agregação familiar sugestiva de algum componente genético. No entanto, são incapazes de decidir isoladamente se a agregação se dá por via genética ou pela via do ambiente compartilhado. Para aprimorar o exame desta distinção, são empregados os estudos em gêmeos e os de adoção. Os primeiros lançam mão do fato de gêmeos monozigóticos (MZ) compartilharem 100\% de seus genes, ao passo que gêmeos dizigóticos (DZ) compartilham 50\%, estando ambos sujeitos a influências ambientais semelhantes. Distintas prevalências de um determinado traço ou transtorno entre as duas espécies de gêmeos poderiam originar-se da diferença genética entre eles. Como a pressuposição fundamental de que os gêmeos ficam submetidos a influências ambientais semelhantes não pode ser determinada a priori, os estudos de adoção são necessários para o reforço da tese genética. Esses trabalhos examinam populações de risco genético (ex: filhos de alcoolistas) criados em ambientes distintos do familiar original (no caso de alcoolismo, por exemplo, adotivos criados desde 
poucos dias ou semanas de vida em lares sem história de problemas com o álcool). No caso de uma elevada prevalência do transtorno, pode-se afirmar a importância de fatores genéticos. A reunião de todas estas modalidades de estudos fornece sólida evidência para a aceitação ou refutação da importância da genética para o traço ou transtorno estudado.

\section{Estudos em famílias}

Os estudos em famílias vêm demonstrando com segurança a agregação familiar do alcoolismo, encontrando aumento de três a quatro vezes na prevalência de alcoolismo em parentes de primeiro grau de alcoolistas. ${ }^{2}$ Entretanto, a relação entre a agregação para alcoolismo e outras drogas mostra um panorama menos definido. Alguns estudos encontraram um padrão de transmissão conjunta de dependência de álcool com dependência de outras drogas, como cocaína ${ }^{3,4}$ ou heroína ${ }^{5}$, onde o risco de alcoolismo em parentes de primeiro grau é aumentado em familiares de dependentes de cocaína e heroína, enquanto outros acharam padrões específicos de agregação para cada droga: para opiáceos ${ }^{6}$, álcool, maconha, cocaína e nicotina. ${ }^{7}$ Nesses casos o risco de desenvolvimento da dependência específica por cada droga, para um parente de primeiro grau, é significativamente maior que o risco para qualquer droga. Num estudo recente, Merikangas et al., ${ }^{8}$ encontraram evidências para dois padrões de transmissão: um específico para cada dependência e outro geral para todas, numa síntese que parece ser o melhor resumo dos estudos em famílias, onde a transmissão hereditária deva ocorrer dentro de um espectro que, num extremo acarrete uma vulnerabilidade geral para qualquer dependência e, no outro, proporcione condições para que uma forma específica de dependência se desenvolva.

\section{Estudos em gêmeos}

Diversos estudos encontraram influências genéticas moderadas ou fortes em alcoolismo para o sexo masculino, com estimativas de herdabilidade que variaram de $40 \%$ a $60 \% .^{9-12} \mathrm{~A}$ herdabilidade é um conceito epidemiológico que avalia, dentro de uma população, o quanto da variância de um traço ou transtorno é devido a fatores genéticos; portanto, não fornece informações a respeito da maneira como a transmissão genética se efetiva. Já para o sexo feminino resultados mais controversos foram encontrados, com estudos que mostraram importante contribuição genética ${ }^{13,14}$ e um que não encontrou tal achado. ${ }^{15}$ No entanto, esse único estudo utilizou e pequena amostragem (31 MZ e $24 \mathrm{DZ}$ ), não podendo concluir se os resultados foram devidos a viés de seleção.

Os estudos para dependência de outras drogas encontraram diversos valores para a herdabilidade entre elas, ${ }^{16-22}$ tendo nos extremos a menor herdabilidade específica para sedativos em mulheres $(30 \%)^{20}$ e a maior para abuso de cocaína em mulheres $(79 \%) .^{21}$ De uma maneira geral, pode-se afirmar a presença de componente genético em todas as dependências de drogas. Um estudo ${ }^{23}$ encontrou evidências para uma vulnerabilidade comum para dependência de álcool e nicotina no sexo masculino.

\section{Estudos de adoção}

Esses estudos são, devido à sua capacidade de separar as influências genéticas das ambientais, os mais relevantes para o exame de uma atuação genética dentro de um transtorno. No entanto, as dificuldades próprias à realização de tais estudos fazem com que poucos tenham sido realizados. Os trabalhos que examinaram a questão em alcoolismo ou em dependência de outras drogas ${ }^{24-27}$ encontraram invariavelmente uma prevalência significativamente maior de dependência de álcool ou de drogas em filhos de pais biológicos com diagnóstico semelhante do que em controles, no sexo masculino e feminino. ${ }^{28}$ Utilizando-se de uma modelagem de dados mais complexa, Cadoret et $a .^{26}$ demonstraram dois trajetos genéticos que levariam à dependência de álcool e outras drogas: um com proveniência direta de um pai com diagnóstico semelhante e o outro através de um diagnóstico paterno/materno de transtorno de personalidade anti-social; esses achados fornecem importante insumo para o exame de distintas vulnerabilidades para os transtornos, sendo fundamentais para guiar os estudos moleculares.

\section{A complexidade da transmissão e o modelo epigenético}

Se os estudos acima apresentados permitem concluir, de modo genérico, pela importância de fatores hereditários como causa de dependências químicas, eles pouco dizem a respeito dos modos de transmissão hereditária. A grande heterogeneidade dos resultados encontrados praticamente afasta um modelo de transmissão mendeliana para os transtornos, onde apenas um gene seria responsável pelo surgimento do transtorno. Pelo contrário, a variação de resultados inclui as dependências químicas no modelo das chamadas doenças complexas, como diabetes ou hipertensão arterial, que vêm recebendo especial atenção nos últimos anos. Nessas doenças, o efeito genético é proveniente de vários genes atuando em conjunto para a produção de uma situação de vulnerabilidade que, em conjunto com a ação ambiental, produzem o fenótipo final. Ou seja, a herdabilidade efetiva é das condições de vulnerabilidade, e não da doença ou transtorno em si. No caso das dependências químicas (lembrando que nos fixaremos aqui aos casos de álcool e cocaína) portanto, devemos falar, em nome do rigor lingüístico, de genética das condições de vulnerabilidade ou suscetibilidade. Este modelo, compreendendo a herança genética das vulnerabilidades e sua modulação ao longo dos anos pelos efeitos ambientais, é chamado de modelo epigenético.

Para o suporte sólido do modelo epigenético é necessário que estudos demonstrem o componente genético de outros fenótipos associados às dependências: os fenótipos de vulnerabilidade ou de alto risco, que apresentaremos a seguir.

\section{Álcool}

Diversas condições de suscetibilidade vêm sendo demonstradas para dependência de álcool, podendo ser grosseiramente repartidas em dois subgrupos: As relativas ao traço de personalidade e aquelas relacionadas à ação bioquímica da droga no organismo.

Cinco traços de personalidade vêm sendo relacionados à 
vulnerabilidade ao alcoolismo: a) nível de atividade comportamental; b) emotividade; c) capacidade de arrefecimento emocional; d) persistência da atenção e e) sociabilidade.

a) nível de atividade comportamental - evidências de distintas fontes correlacionaram esta variável com o risco aumentado para o desenvolvimento de alcoolismo. Estudos longitudinais, ${ }^{29}$ retrospectivos $^{30}$ e mesmo de adoção ${ }^{31,32}$ encontraram essa associação. Além disso, um estudo ${ }^{33}$ observou escores significativamente mais elevados de nível de atividade comportamental em filhos de alcoolistas em relação a filhos de não-alcoolistas. Mais recentemente, no único estudo onde o nível de atividade foi avaliado diretamente (e não por meio de escalas) através de um atígrafo ligado ao punho dos participantes, Moss et al. ${ }^{34}$ confirmaram o resultado acima para filhos de alcoolistas ou abusadores de drogas em relação a não-alcoolistas/abusadores de drogas.

b) Emotividade - definindo esse traço como a propensão a grande reação emocional aos estímulos do ambiente, Sher et al. ${ }^{35}$ encontraram maior resposta emocional em filhos de alcoolistas em relação a não-alcoolistas, medido como escores para neuroticismo. No mesmo sentido, Finn et al. ${ }^{36}$ encontraram suscetibilidade aumentada para ativação do sistema nervoso autônomo em indivíduos de alto risco para desenvolvimento de alcoolismo.

c) Capacidade de arrefecimento emocional - um único estu$\mathrm{do}^{37}$ encontrou uma maior dificuldade, em jovens do sexo masculino de alto risco para alcoolismo, para retornar à linha de base emocional após ativação autonômica, indicando a possibilidade deste traço estar envolvido na vulnerabilidade ao alcoolismo.

d) Persistência da atenção - estudos demonstram a maior prevalência de distúrbios de atenção em populações de alto risco para desenvolvimento de alcoolismo, ${ }^{38-40}$ indicando um fator de vulnerabilidade. Ademais, uma investigação neurofisiológica encontrou alterações de onda P300 em filhos de alcoolistas, ${ }^{41}$ um marcador fisiológico relacionado a mecanismos de atenção.

e) Sociabilidade - alguns estudos realizados em alcoolistas e indivíduos de alto risco e estudos prospectivos de pessoas que vieram a desenvolver alcoolismo demonstram variações na maneira de sociabilização que poderiam ser resumidas sob o nome de desinibição comportamental, seja como agressividade, ${ }^{42}$ busca de sensações, ${ }^{43}$ impulsividade ${ }^{44}$ ou inconformismo social. ${ }^{45}$

Ao lado dos traços de personalidade associados à vulnerabilidade, o componente bioquímico mais estudado é a variação das enzimas metabolizadoras do álcool no organismo. A enzima álcool desidrogenase é responsável pela metabolização de álcool a acetaldeído que, em altos níveis sanguíneos, provoca reações desagradáveis, como náuseas e vômitos. No entanto, os níveis de acetaldeído mantêm-se baixos devido à ação de outra enzima, a aldeído desidrogenase (ALDH). Essa enzima possui duas variantes (ALDH1 e ALDH2) geneticamente controladas, sendo que a ALDH2 é inativa biologicamente, o que faz com que os $10 \%$ da população asiática homozigota para este gene tenha intensos efeitos adversos, tornando-se protegida para o desenvolvimento de alcoolismo e com que menos de $10 \%$ de alcoolistas em população japonesa sejam heterozigotos para estes genes, comparados a $40 \%$ de heterozigose na população japonesa geral ${ }^{46}$ Outro fenótipo que vem sendo mais recentemente estudado, o nível de resposta ao álcool, traz perspectivas promissoras para o campo. Schuckit ${ }^{47}$ encontrou associação entre um menor nível de resposta aos efeitos do álcool e desenvolvimento de alcoolismo, abrindo terreno para que se iniciem estudos dos trajetos bioquímicos envolvidos nos efeitos do álcool, além da aldeído desidrogenase.

Uma outra estratégia que vem encontrando resultados interessantes é a de procurar vulnerabilidades em comum entre dependência de álcool, drogas e outros traços fenotípicos comportamentais. Assim, Comings et al. ${ }^{48}$ encontraram evidências para uma vulnerabilidade genética comum para transtorno de déficit de atenção e hiperatividade, gagueira, tiques, transtorno de conduta e obsessivo-compulsivo, mania, ansiedade generalizada e abuso de álcool. Nesse modelo, diversos transtornos da psiquiatria apresentariam uma base genética comum, ficando a cargo do desenvolvimento epigenético o papel da produção de um fenótipo ou de outro. Voltaremos a este estudo ao tratarmos dos estudos moleculares.

\section{Cocaína}

Ainda que nenhum estudo sobre investigação de vulnerabilidades específicas para dependência de cocaína tenha sido produzido, a evidência da validade da distinção dos abusadores de cocaína em tipos A e B, ${ }^{49}$ extraídos de sistema tipológico validado para alcoolismo, ${ }^{50}$ permite algumas aproximações. Os dependentes de cocaína do tipo B, assim como no caso da dependência de álcool, apresentam uma maior prevalência de história familiar de abuso de substâncias, problemas prévios de personalidade e transtornos de comportamento na infância, levando a pensar num grupo de suscetibilidade geral a dependências químicas, resultado consoante ao encontrado nos estudos de adoção acima apresentados. Assim, é possível sustentar como hipótese que as características de traços de personalidade encontradas nos estudos de suscetibilidade a alcoolismo sirvam também para explicar ao menos uma parte da suscetibilidade à dependência de cocaína, ficando a outra parte devida às peculiaridades da ação bioquímica da droga no organismo. $\mathrm{O}$ único estudo que examinou dependência conjunta de álcool e de outras drogas para nível de ativação comportamental $^{34}$ confirmou esta hipótese. Ficam ainda em aberto os estudos que relacionam variações individuais na metabolização da cocaína. A aplicação da estratégia de uma vulnerabilidade comum a diversos fenótipos da psiquiatria encontrou suporte em um estudo $^{51}$ que encontrou suscetibilidade comum para a síndrome de Gilles de la Tourette, déficit de atenção e hiperatividade infantis e abuso de diversas drogas, incluindo cocaína.

A reunião de todos estudos reforça a hipótese de importante heterogeneidade etiológica para estes transtornos, podendo o seu desenvolvimento originar-se de diferentes vias bioquímicas, através de variados padrões de personalidade onde, em momento algum, a ação do meio ambiente, físico, psicossocial ou cultural, pode ser desprezada. 


\section{Estudos moleculares}

Orientados pela força dos achados dos estudos epidemiológicos, que comprovam a existência de participação genética nos transtornos de dependência, e estimulados pelo avanço das técnicas em genética molecular, os pesquisadores vêm investindo com veemência nos estudos moleculares para abuso ou dependência de drogas. O primeiro artigo publicado com algum achado positivo, por Blum et al., em 1990,,$^{52}$ conheceu grande repercussão internacional e um precoce otimismo para o encontro de um gene do alcoolismo. Estes autores encontraram associação entre uma variante do gene do receptor dopaminérgico D2 - D2A1- e alcoolismo. No entanto, o otimismo inicial logo foi atenuado pela incapacidade de outros centros em replicar o resultado, ${ }^{53,54}$ sugerindo que a resolução do problema não poderia resumir-se à procura de genes únicos. Dentro desta atmosfera de crescente complexidade, diversos estudos em genética molecular foram e estão sendo realizados, como apresentaremos a seguir.

Antes, no entanto, descreveremos as duas formas de realização de trabalhos em genética molecular: os estudos de ligação e os de associação. Nos primeiros, procuram-se genes de maior efeito, ou seja, para um determinado transtorno, buscase aquele gene que possa ser capaz de, por si só, causar o desenvolvimento do distúrbio. Os estudos de associação investigam a participação de genes candidatos dentro do transtorno, ou seja, eles verificam em que percentual um determinado gene tem influência. É, portanto, o desenho mais apropriado para o estudo de fenótipos complexos, como o alcoolismo. Ainda que estudos de ligação na área de dependências químicas não devam ser integralmente desprezados (sobretudo na investigação de condições de suscetibilidade), nos limitaremos aqui a apresentar os estudos de associação pertinentes à área. Como esses trabalhos, em sua maioria, investigam dependências de várias drogas ao mesmo tempo, trataremos deles em conjunto, sempre indicando, quando possível, as diferenças encontradas para as singularidades de cada droga. Em nome da clareza de exposição, dividiremos os trabalhos por sistema fisiológico estudado.

\section{a) Sistema dopaminérgico}

É o mais estudado dentre os trajetos envolvidos no sistema de recompensa cerebral, ${ }^{55}$ com destaque para a investigação de variações polimórficas nos genes de seus cinco tipos de receptores (DRD1; DRD2; DRD3; DRD4 e DRD5). Polimorfismos são variações na sequiência de bases de um determinado gene que podem acarretar diferenças em sua expressão e, por conseqüência, variações funcionais da proteína por ele gerada. Associações são encontradas entre determinados polimorfismos e dependência de drogas para todos os receptores.

DRD1 - Comings et al. ${ }^{56}$ encontraram associação entre uma variação do gene para este receptor com diversos comportamentos impulsivos, incluindo abuso de drogas.

DRD2 - devido à sua originalidade como primeiro achado positivo no campo do alcoolismo, a associação entre alelos desse gene e dependência de drogas vem sendo muito estudada, fornecendo os mais densos resultados de toda o campo de pesquisa. Em uma meta-análise compreendendo 15 estudos americanos e europeus, num total de 1.015 alcoolistas e 898 controle, Noble ${ }^{57}$ encontrou uma prevalência três vezes maior do alelo A1 desse gene em alcoolistas graves com relação a controles, ao passo que nenhuma diferença foi observada entre os controles e alcoolistas leves. Igualmente, encontrou associação entre o alelo B1 e dependência de álcool. Essas associações também foram encontradas por outros autores para dependência de cocaína ${ }^{58}$ e abuso de polisubstâncias, ${ }^{59,60}$ junto a comportamento agressivo. ${ }^{51}$ Entretanto, associações negativas também podem ser observadas. ${ }^{61}$

Esses resultados indicam fortemente a presença de variações funcionais produzidas pelos polimorfismos. Três estudos reforçam essa hipótese: Noble et al., ${ }^{62}$ encontraram associação entre DRD2A1 e tempo de latência aumentado para ondas P300 em filhos de dependentes de álcool, em relação a controles, indicando um trajeto fisiológico para a atuação da herança dopaminérgica; Pohjalainen et al. ${ }^{63}$ estudando voluntários saudáveis em uma população finlandesa, encontraram associação entre DRD2A1 e baixa disponibilidade de receptores D2; como a baixa disponibilidade de receptores D2 já foi associada a certos traços de personalidade ${ }^{64}$ esse achado reforça a hipótese da transmissão da herdabilidade através de traços de personalidade. Noble et al. ${ }^{65}$ também analisando sujeitos sem diagnóstico de abuso de álcool ou drogas, acharam metabolismo regional cerebral de glicose reduzido em portadores do alelo A1 desse receptor para áreas envolvidas no sistema de recompensa cerebral, como nucleus accumbens, ou reguladoras de função frontal, como córtex pré-frontal. Este trabalho traz importante colaboração para novos trabalhos no reconhecimento das diferenças individuais na suscetibilidade ao alcoolismo.

DRD3 - apesar de sua presença majoritária em regiões límbicas ${ }^{66} \mathrm{e}$, portanto, possível papel na regulação de emoções, o gene para este receptor ainda não recebeu muita atenção dos pesquisadores. Thome et al. ${ }^{67}$ encontraram prevalência significativamente maior do alelo A1 em pacientes alcoolistas em relação a controles, enquanto Parsian et al.$^{68}$ não encontraram nenhuma associação.

DRD4 - o interesse nesse gene vem do fato da observação de sua influência na gênese do distúrbio de atenção/hiperatividade infantis,${ }^{69}$ traço envolvido na vulnerabilidade às dependências. Os poucos estudos realizados investigando diretamente dependências são controversos, com associações negativas ${ }^{68}$ e positivas ${ }^{70}$ entre alelos longos (sete repetições) do gene e alcoolismo, no primeiro estudo, e dependência de opióides, no segundo caso.

DRD5 - o único estudo ${ }^{71}$ examinando polimorfismos neste gene encontrou resultados interessantes. Como os receptores dopaminérgicos D5 expressam-se particularmente no hipocampo, região aparentemente envolvida nas respostas a novos estímulos, ${ }^{72}$ os autores testaram uma possível associação entre algum polimorfismo do gene e abuso de substâncias mediado pelo traço de personalidade de busca de novidade. Encontraram esse achado positivo para o sexo feminino, no primeiro estudo molecular destacando diferentes vias de vulnerabilidade entre os sexos. 


\section{b) Outros sistemas}

A exigüidade do estudo dos outros sistemas cerebrais potencialmente envolvidos na dependência de drogas faz com que os coloquemos todos, momentaneamente, em uma única categoria, destacando os principais estudos. Kranzler et al. ${ }^{73}$ encontraram modesta associação $(\mathrm{p}=0,03)$ entre alelos do gene do receptor opióide mu com dependência de álcool/drogas, enquanto três outros trabalhos foram incapazes de observar qualquer associação. ${ }^{74-76} \mathrm{O}$ sistema gabaérgico, principal sistema inibitório cerebral, recebeu atenção em dois estudos, um com resultados negativos ${ }^{77}$ e outro com associação entre polimorfismo no subtipo alfa3 e alcoolismo.$^{78}$

Evidências preliminares de variantes do sistema adrenérgico ${ }^{79}$ serotoninérgico ${ }^{80}$ e do gene da monoaminooxidase $^{81}$ com dependência de álcool ou drogas, ou do gene da catecol-O-metiltransferase com comportamentos de risco para abuso de drogas, ${ }^{82}$ aguardam ulteriores investigações para a confirmação de seu papel.

\section{c) Interação de genes}

As chamadas doenças complexas têm como característica a intervenção de mais de um gene para a transmissão de sua herdabilidade. Um dos mecanismos pelo qual essa atuação conjunta de genes se dá é a chamada interação. Nesse mecanismo, a reunião de alguns genes específicos é capaz de produzir um fenótipo que, em ação isolada, tais genes não seriam capazes de gerar com tal intensidade; caracteriza menos uma atuação qualitativa, no sentido da existência ou não de algum traço, e mais um funcionamento quantitativo, onde o efeito (não patológico por si) de genes favorece o desenvolvimento do transtorno. Alguns trabalhos examinaram este efeito para as dependências. Noble et al. ${ }^{83}$ investigaram a prevalência de variações polimórficas dos genes para receptores dopaminérgico (DRD2) e gabaérgico (subunidade beta3 - GABRB3); encontraram uma maior prevalência do alelo DRD2-A1 (já apresentado em estudos acima) e uma menor prevalência do alelo GABRB3-G1 em alcoolistas graves, quando comparados a controles sem o fenótipo, em análises separadas. Entretanto, ao analisar a combinação das duas variantes, o efeito sobre o risco de alcoolismo mostrou-se mais robusto, indicando a presença de interação. Num trabalho bastante criativo, Schuckit et al. ${ }^{84}$ investigaram interação de diferentes sistemas na gênese de um traço de vulnerabilidade do alcoolismo, o nível de resposta (NR) ao álcool. Para o alelo LL do gene do transportador de serotonina (5-HTT) e para o Pro/Ser do gene do receptor gabaérgico alfa6 (GABRA6), encontraram associação com baixo NR e maior prevalência de alcoolismo. Analisando os sujeitos portadores, ambos os polimorfismos encontraram o NR mais baixo e $100 \%(n=4)$ de história de alcoolismo, mais uma vez indicando efeito de interação na intensidade do fenótipo. Um trabalho ${ }^{48}$ detectou evidências de interação para alcoolismo e traços possivelmente envolvidos na suscetibilidade ao desenvolvimento de dependências. Os autores observaram efeito aditivo entre polimorfismos de três genes dopaminérgicos (DRD2; dopamina beta-hidroxilase-DbetaH e trasportador de dopamina-DAT1) e gagueira, transtorno de atenção/hiperatividade infantis, transtorno de conduta e alcoolismo.

\section{Conclusões}

1. A mais forte conclusão da análise conjunta dos estudos epidemiológicos e moleculares é a presença notável de fatores hereditários na gênese do abuso ou dependência de drogas.

2. A heterogeneidade dos resultados em termos de definição dos limites dos fenótipos e mecanismos de transmissão hereditária indica o abuso ou dependência de drogas como resultante de uma complexa interação de fatores genéticos, psicossociais e culturais, melhor compreendida dentro de um modelo desenvolvimental de psicopatologia. ${ }^{85}$

3. Os trajetos para o gênese do abuso/dependência de drogas são múltiplos, compreendendo caminhos específicos para cada droga e outros gerais para todas as drogas; possivelmente os casos individuais sejam misturas, em variadas proporções, destes distintos trajetos.

4. Além de trajetos gerais e específicos para a transmissão hereditária da vulnerabilidade a abuso ou dependência de drogas, coexistem suscetibilidades comuns a diversos fenótipos da psiquiatria; em alguns casos, não é possível rejeitar a hipótese da transmissão de traço comum a todos os transtornos psiquiátricos.

5. Não há genes únicos para abuso ou dependência de drogas, assim como não há evidência de genes exclusivos para este fenótipo. Pelo contrário, os estudos moleculares apontam para a transmissão genética (mediada por características de personalidade e diferentes reações individuais aos efeitos das drogas) de variações no balanço de sistemas de neurotransmissão e de metabolização bioquímica de drogas. A ação do meio ambiente sobre estas condições biológicas produz a expressão do fenótipo.

6. A variante menor do gene do receptor dopaminérgico DRD2, conhecida por DRD2-A1 representa um importante papel na transmissão da vulnerabilidade à dependência de drogas, assim como a outros fenótipos. Esta herdabilidade se dá provavelmente através de mecanismos neurofisiológicos que produzem variações funcionais nos sistemas cerebrais, acarretando padrões afetivos e neuropsicológicos vulneráveis ao surgimento do transtorno.

7. Evidências preliminares indicam um papel para outros genes do sistema dopaminérgico, serotoninérgico, gabaérgico e opióide que, atuando em conjunto, podem elevar a suscetibilidade individual de seus portadores às dependências.

8. A força dos resultados acima revisados leva diretamente à questão do tratamento para as dependências, por duas vias. Inicialmente, o reconhecimento gradual dos trajetos bioquímicos envolvidos na gênese e manutenção das dependências abre caminho para o aperfeiçoamento de psicofármacos que, atuando pontualmente em receptores e transportadores fundamentais ao processo, podem agir com mais eficácia sobre o transtorno.

Em segundo lugar, o reconhecimento, em nível molecular, das condições de vulnerabilidade para o transtorno permite ações preventivas sobre populações de risco, seja em evitar o contato com drogas, seja na redução dos traços de suscetibilidade. 


\section{Perspectivas futuras}

Os estudos em genética de dependências químicas prometem resultados mais sólidos nos próximos anos, avançando através de certas alternativas metodológicas, em ação sinérgica. De um lado, a investigação mais detalhada de subfenótipos, ou seja, de condições neuropsicológicas e neurofisiológicas (incluindo estados subjetivos) associadas à vulnerabilidade; estes subfenótipos derivam de modo mais imediato de funções biológicas, tornando mais confiáveis os achados a eles associados, distintamente dos complexos construtos nosográficos da psiquiatria que, considerada a contínua ação do meio ambi- ente sobre a biologia, pouco dizem a respeito da base biológica dos transtornos psiquiátricos em geral. De outro lado, a investigação de efeitos de interação de certos agressores ambientais agindo sobre situações específicas de vulnerabilidade, gerando o transtorno. Em outras palavras, à medida que os pesquisadores da área forem abandonando as categorias diagnósticas estritas da psiquiatria e investigarem o fenômeno dos transtornos mentais como a composição de tendências neuropsicofisiológicas com fatores ecopsicossociais, as estratégias de pesquisa facilitarão a elucidação de diversos enigmas do setor, aí incluídas seguramente as dependências de drogas.

\section{Referências bibliográficas}

1. Shaffer H. The most important unresolved issue in the addiction: conceptual chaos. Substance Use \& Misuse 1997; 32(11):1573-80.

2. Merikangas K. The genetic epidemiology of alcoholism. Psychol Med 1990; 20: 11-22.

3. Miller N, Gold M, Belkin B, Klahr A The diagnosis of alcohol and cannabis dependence in cocaine dependents and alcohol dependence and their families. Brit J Addiction 1989; 84: 149198.

4. Kosten T, Anton S, Rousanville B. Ascertaining psychiatric diagnosis with the family history method in a substance abuse population. J Psychiat Res 1992; 26:135-47.

5. Maddux J, Desmond D. Family and environment in the choice of opioid dependence or alcoholism. Am J Drug \& Alcohol Abuse 1989; 15: 117-34.

6. Hill S, Cloninger C, Ayre F. Independent familial transmission of alcoholism and opiate abuse. Alcohol Clin Exp Res 1977; 1: 335-42.

7. Bierut L, Dinwiddie S, Begleiter H, Schuckit M, Reich T. Familial transmission of substance dependence: alcohol, marijuana, cocaine, and habitual smoking. . Arch Gen Psychiatry 1998; 55: $982-88$

8. Merikangas K, Stolar M, Stevens D, O'Malley S, Rousanville B. Familial transmission of substance use disorders. Arch Gen Psychiatry 1998; 55: 973-79.

9. Hrubec Z, Ommen G. Evidence of genetic predisposition to alcoholic cirrhosis and psychosis: twin concordances for alcoholism and its biological endpoints by zycosity among male veterans. Alcohol Clin Exp Res 1981; 5: 207-15.

10. Reed T, Page W, Viekn R, Christian J. Genetic predisposition to organ-specific endpoints of alcoholism. Alcohol Clin Exp Res 1996; 20: 1528-33.

11. Kendler K, Prescott C, Neale M, Pedersen N. Temperance board registration for alcohol abuse in a national sample of swedish male twins, born 1902 to 1949. Arch Gen Psychiatry 1997; 54: 178-84.

12. Prescott C, Kendler K. Genetic and environmental contributions to alcohol abuse and dependence in a populationbased sample of male twins. Am J Psychiatry 1999; 156: 34-40.

13. Kendler K, Neal M, Eaves L. A twin family study of alcoholism in women. Am J Psychiatry, 1994 151(5): 707-15.

14. Prescott C, Neale M, Corey L, Kendler K. Predictors of prblem drinking and alcohol dependence in a population-based sample of female twins. J Stud Alcohol 1997; 58(2): 167-81.

15. Pickens R, Svikis D, McGues M, Lykken D, Heston L, Clayton P. Heterogeneity in the inheritance of alcoholism. Arch Gen Psychiatry 1991; 48: 19-28.
16. Tsuang M, Lyons M, Eisen S, Goldberg J, True W, Nang L, Eaves L. Genetic influences on abuse of illicit drugs. Am J Med Genet 1996; 5: 473-7.

17. Grove W, Eckert E, Heston L, Bouchard T, Segal N, Lykken D. Heritability of substance abuse and antisocial behavior: a study of monozygotic twins reared apart. Biol Psychiatry 1990; 27: 1293304 .

18. Gynther L, Carey G, Gottesman I, Vogler G. A twin study of nonalcohol substance abuse. Psychiatr Res 1995; 56: 213-20.

19. Tsuang M, Lyons M, Eisen S, Goldberg J, True W, Lin N, Meyer J, Toomey R, Faraone S, Eaves L. Genetic influences on DSM-IIIR drug abuse and dependence: a study of 3372 twin pairs. Am J Med Genet 1996; 67: 473-77.

20. van den Bree M, Johnson E, Neale M, Pickens R. Genetic and environmental influences on drug use and abuse/dependence im male and female twins. Drug and Alcohol Dependence 1998; 52: 231-41.

21. Kendler K, Prescott C. Cocaine use, abuse and dependence in a population-based sample of female twins. Brit J Psychiatry 1998; 173: $345-50$.

22. Tsuang M, Lyons M, Meyer J, Toomey R, Eaves L. Co-ocurrence of abuse of different drugs in men. Arch Gen Psychiatry 1998; 55: 967-72.

23. True W, Xian H, Lyons M, Goldberg J, Tsuang M. Common genetic vulnerability for nicotine and alcohol dependence in men. Arch Gen Psychiatry 1999; 56: 655-61.

24. Goodwin D, Schulsinger F, Lermansen L, Guze S, Winokur G. Alcohol problems in adoptees raised apart from alcoholic biological parents. Arch Gen Psychiatry 1973; 28(2): 238-43.

25. Cadoret R, Cain C, Grove W. Development of alcoholism in adoptees raised apart from alcoholic biologic relatives. Arch Gen Psychiatry 1980; 37(5): 561-63.

26. Cadoret R, Yates W, Troughton E, Woodworth G, Stewart M. Adoption study demonstrating two genetic pathways to drug abuse. Arch Gen Psychiatry 1995; 52: 42-52.

27. Cadoret R, Troughton E, O'Gorman T, Heywood E. An adoption study of genetic and environmental factors in drug abuse. Arch Gen Psychiatry 1996; 43: 1131-36.

28. Cadoret R, Yates W, Troughton E, Woodworth G, Stewart M. An adoption study of drug abuse/dependence in females. Comprehensive Psychiatry 1996; 37(2): 88-94.

29. Jones M. Personality correlates and antecedents of drinking patterns in adult males. Journal Cons Clin Psychiatry 1968; 32: 2-12.

30. Tarter R, McBride H, Buonpane N, Schneider D. Differentiation of alcoholics. Childhood history of minimal brain dysfunction, family history, and drinking pattern. Arch Gen Psychiatry 1977; 34(7):761-68 
31. Cantwell D. Psychiatric Illness in families of hyperactive children. Arch Gen Psychiatry 1972; 27: 414-17.

32. Goodwin D, Schulsinger F, Hermansen L, Guze S, Winokur G. Alcoholism and the hyperactive child syndrome. J Nerv Men Disease 1975; 160: 349-53.

33. Tarter R, Kabene M, Escallier E, Laird S, Jacob T. Temperament deviation and risk for alcoholism. Alcoh Clin Exp Res 1990; 14: 380-2.

34. Moss H, Blackson T, Martin C, Tarter R. Heightened motor activity level in male offspring of substance abuse fathers: association with temperament, behavior and psychiatric diagnosis. Biol Psychiatry 1992; 32: 1135-47.

35. Sher K, Walitzer K, Wood P, Brent E. Characteristics of children of alcoholics: putative risk factors, substance use and abuse, and psychopathology. J Abnormal Psychology 1991; 100: 427-88.

36. Finn P, Zeitouni N, Pihl R. Effects of alcohol on psychophysiological hyperactivity to nonaversive and aversive stimuli in men at high risk for alcoholism. Journal Ab Psychology 1990; 99: 79-85.

37. Sher K, Levenson R. Risk for alcoholism and individual differences in the stress-response-dampening effect of alcohol. J Abnormal Psychology 1982; 19: 350-67.

38. Alterman A, Tarter R. The transmission of psychological vulnerability. Implications for alcoholism etiology. J Nerv Ment Disease 1983; 171: 147-54.

39. Alterman A, Tarter R, Petrarulo E, Baughman T. Evidence for impersistence in young male alcoholics. Alcohol Clin Exp Res 1984; 8: 448-50.

40. Tarter R, Hegedus A, Goldstein G, Shelly C, Alterman A Adolescent sons of alcoholics: neuropsychological and personality characteristics. Alcoh Clin Exp Res 1984; 8: 216-22.

41. Begleiter H, Porjesz B, Kissin B. Event-related brain potentials in children at risk for alcoholism. Science 1984; 225: 1493-5.

42. Kellam S, Ersminger M, Simon M. Mental health in first grade and teenage drug, alcohol, and cigarette use. Drug and Alcohol Dependence 1980; 5: 273-304.

43. Zuckerman M, Bone R, Neary R, Mangelsdorff D, Brutsman B. What is the sensation seeker? Personality trait and experience correlates of the sensation-seeking scales. J Consult Clin Psychol 1972; 39(2): 308-21.

44. McCord J. Etiological factors in alcoholism: family and personal characteristics. Quarterly J Stud Alcohol 1972; 33: 1020-7.

45. Robins L. Deviant children grow up: a sociological and psychiatric study of sociopathic personality. Baltimorer: Williams and Wilkins; 1966

46. Murayama M, Matsushita S, Muramatsu T, Higuchi S. Clinical characteristics and disease course with inactive aldehyde dehydrogenase-2. Alcohol Clin Exp Res 1998; 22: 524-7.

47. Schuchkit M. Biological, psychological, and environmental predictors of the alcoholism risk: a longitudinal study. J Stud Alcohol 1998; 59: 485-94.

48. Comings D, Wu S, Dietz G, Muhleman D. Polygenic inheritance of Tourette Syndrome, stuttering, attention deficit hyperactivity, conduct, and opposicional defiant disorder. Am J Med Gen (Neuropsychiatric Genetics) 1996; 67:264-88.

49. Ball S, Carrol K, Babor T, Rousanville B. Subtypes of cocaine abusers: support for a type A-type B distinction. J Consult Clin Psychol 1995; 63(1): 115-24.

50. Cloninger C, Sigvardson S, Gilligan S, von Knorring A, Reich T, Bohman M. Genetic heterogeneity and the classification of alcoholism. Adv Alcohol Subst Abuse 1988; 7(3-4): 3-16.

51. Comings D. Genetic factors in substance abuse based on studies of Tourette Syndrome and ADHD probands and relatives. I. Drug abuse. Drug and Alcohol Dependence 1993; 35: 1-16.

52. Blum K, Noble E, Sharidan P, Montgomery A, Ritchie T, Cohn J. Allelic association of human dopamine D2 receptor gene and alcoholism. JAMA 1990; 263(15): 2055-60.
53. Bolos A; Dean M; Lucas-Derse C, Ramsburg M, Brown G, Goldman D. Population and pedigree studies reveal a lack of association between the dopamine D2 receptor and alcoholism. JAMA 1990; 264(24): 3156-60.

54. Gelernter J, O’Malley S, Risch N, Kranzler H, Krystal J, Merikangas $\mathrm{K}$, Kennedy J, Kidd K. No association between na allele at the D2 dopamine receptor gene (DRD2) and alcoholism. JAMA 1991; 266(13): 1801-7.

55. Koob G. Drugs of abuse: anatomy, pharmacology and function of reward pathways. Trends in Pharmac Science 1992; 13: 177-84.

56. Comings D, Gade R, Wu S, Chiu C, Muhleman D, Saucier G, Ferry L, Rosenthal R, Lesleur H, Rugle L, MacMurray P. Studies of the potential role of the dopamine D1 receptor gene in addictive behaviors. Mol Psychiatry 1997; 2: 44-56.

57. Noble E, Zhang X, Ritchie T, Lawford B, Grosser S, Young R, Sparkes R. D2 dopamine receptor and $\mathrm{GABA}(\mathrm{A})$ receptor beta3 subunit genes and alcoholism. Psychiatr Res 1998; 81(2): 133-47.

58. Noble E, Blum K, Khalsa E, Ritchie T, Treiman L, Sparkes L. Allelic association of the D2 dopamine receptor gene with cocaine dependence. Drug and Alcohol Dependence 1993; 33: 271-85.

59. Smith S, O'Hara B, Persico A, Gorelick D, Newlin D, Vlahov D, Solomon L, Pickens R, Uhl G. Genetic vulnerability to drug abuse. The D2 dopamine receptor Taq I B1 restriction fragment lenght polymorphism appears more frequently in polysubstance abusers. Arch Gen Psychiatry 1992; 49: 723-7.

60. Noble E. Polymorphisms of the D2 dopamine receptor gene and alcoholism and other substance use disorders. Alcohol Alcohol Suppl 1994;2: 35-43.

61. Gelernter J, Kranzler H, Satel S. No associatiion between D2 dopamine receptor (DRD2) alleles or haplotypes and cocaine dependence or severity of cocaine dependence in european-and african-americans. Biol Psychiatry 1999; 45(3): 340-5.

62. Noble E, Berman S, Ozkaragoz T, Ritchie T. Prolonged P300 latency in children with D2 dopamine receptor A1 allele. Am J Hum Genet 1994; 54: 658-68.

63. Pohjalainen T, Rinne J, Nagren K, Lehikoinen P, Anttila K, Syvalahti E, Hietala J. The A1 allele of the human D2 dopamine receptor gene predicts low D2 receptor availability in healthy volunteers. Mol Psychiatry 1998; 3(3): 256-60.

64. Breier A, Kestler L, Adler C, Elman I, Wiesenfeld N, Malhotra A, Picker D. Dopamine D2 receptor density and personal detachment in healthy subjects. Am J Psychiatry 1998; 155: 1440-2.

65. Noble E, Gottschalk L, Fallon J, Ritchie T, Wu J. D2 dopamine receptor polymorphism ans brain regional glucose metabolism. Am J Med Genet 1997; 74(2): 162-6.

66. Mash D. Are neuroadaptations in D3 dopamine receptors linked to the development of cocaine dependence? Mol Psychiatry 1997; 2: 7-8.

67. Thome J, Weijers H, Wiesbeck G, Sian J, Nara K, Boning J, Riederer P. Dopamine D3 receptor gene polymorphism and alcohol dependence: rerlation to personality rating. Psychiatr Genet 1999; 9(1): 17-21.

68. Parsian A, Chakraverty S, Fisher L, Cloninger C. No association between polymorphisms in the human dopamine D3 and D4 receptors genes and alcoholism. Am J Med Genet 1997; 74(3): 281-5.

69. LaHoste G, Swanson J, Wigal S, Glabe S, Wigal T, King N, Kennedy. Dopamine D4 receptor gene polymorphism is associated with attention deficit hyperactivity disorder. Mol Psychiatry 1996; 1: 121-4.

70. Kottler M, Cohen H, Segman R, Gritsenko I, Nemanov L, Lerer B, Kramer I, Zer-Zion M, Kletz I, Ebstein R. Excess dopamine D4 receptor (DRD4) exon III seven repeat allele in opioid-dependent subjects. Mol Psychiatry 1997; 2(3): 251-4.

71. Vanyukov M, Moss H, Gioio A, Hughes H, Kaplan B, Tarter R. An association between a microsatellite polymorphism at the DRD5 gene and the liability to substance abuse: pilot study. Behavior Genetics 1998; 28(2): 75-82. 
72. Knight R. Contribution of human hippocampal region to novelty detection. Nature 1996; 383: 256-9.

73. Kranzler H, Gelernter J, O'Malley S, Hernandez-Avila C, Kaufman D. Association of alcohol or other drug dependence with alleles of the mu opioid receptor gene (OPRM1). Alcohol Clin Exp Res 1998; 22(6): 1359-62.

74. Berretini W, Hoehe M, Ferraro T, DeMaria P, Gottheil E. Human mu opioid receptor gene polymorphisms and vulnerability to substance abuse. Addict Biol 1997; 2: 303-8.

75. Bergen A, Kokoszka J, Peterson R, Long J, Virkkunen M, Linnoila M, Goldman D. Mu opioid receptor gene variants: lack of association with alcohol dependence. Mol Psychiatry 1997; 2:490-4.

76. Sander T, Gscheidel N, Wendel B, Samochowiec J, Smolka M, Rommelspacher H, Schmidt L, Hoche M. Human muopioid receptor variation and alcohol dependence. Alcohol Clin Exp Res 1998; 22(9): 2108-10.

77. Sander T, Ball D, Murray R, Patel J, Samochowiec J, Winterer G, Rommelspacher H, Schimdt L, Loh E. Association analysis of sequence variants of $\mathrm{GABA}(\mathrm{A})$ alpha6, beta2, and gamm2 gene cluster and alcohol dependence. Alcohol Clin Exp Res 1999; 23(3):427-31.

78. Parsian A, Cloninger C. Human GABAA receptor alpha 1 and alpha 3 subunits genes and alcoholism. Alcohol Clin Exp Res 1997; 21(3): 430-3.

79. Feng J, Sobell J, Heston L, Goldman D, Cook E, Kranzler H, Gelernter J, Sommer S. Variants in the alpha2A AR adrenergic receptor gene in psychiatric patients. Am J Med Gen (Neuropsychiatric Genetics) 1998; 81: 405-10.
80. Rocha B, Scarce-Levie K, Lucas J, Hiroi N, Castanon N, Crabbe J, Nestler E, Hen R. Increased vulnerability to cocaine in mice lacking the serotonin-1B receptor. Nature 1998; 393(6681): 175-8.

81. Vanyukov M, Moss H, Yu L, Tarter R, Deka R. Preliminary evidence for an association of a dinucleotide repeat polymorphism at the MAOA gene with early onset alcoholism/substance abuse. Am J Med Gen (Neuropsychiatric Genetics) 1995; 60: 122-6.

82. Strous R, Bark N, Parsia S, Volavka J, Lachman H. Analysis of a functional catechol-O-methyltransferase gene polymorphism in schizophrenia: evidence for association with aggressive and antisocial behavior. Psychiatr Res 1997; 69: $71-7$.

83. Noble E. The dopamine D2 receptor gene: a review of association studies in alcoholism and phenotypes. Alcohol 1998; 16(1): 33-45.

84. Schuckit M, Mazzanti C, Smith T, Ahmed U, Radel M, Iwata N, Goldman D. Selective genotyping for the role of 5HT2A, 5-HT2C, and GABA alpha 6 receptors and the serotonin transporter in the level of response to alcohol: a pilot study. Biol Psychiatry 1999; 45(5): 647-51.

85. Rutter M, Dunn J, Plomin R, Simonoff E, Pickles A, Maughan B, Ormel J, Meyer J, Eaves L. Integrating nature and nurture: implications of person-environment correlations and interactions for developmental psychopathology. Development and Psychopathology 1997; 9:335-64.

Correspondência: Guilherme Peres Messas

Instituto de Psiquiatria - Rua Dr. Ovídio Pires de Campos, s/n 05403-010

$3^{\circ}$ andar, sala 4051 São Paulo - SP Email: messas@ netpoint.com.br 